\title{
1995125328
}

\section{CFD ASSESSMENT OF THE POLLUTANT ENVIRONMENT FROM RD-170 PROPULSION SYSTEM TESTING}

\author{
Ten-See Wang \\ Paul McConnaughey \\ NASA Marshall Space Flight Center, Huntsville, Alabama 35812 \\ Saif Warsi \\ Sverdrup Technology, Inc., Huntsville, Alabama 35806 \\ and \\ Yen-Sen Chen \\ Engineering Sciences, Inc., Huntsville, Alabama 35805 \\ Phone: 205/544-0503, Fax: 205/544-1215
}

\section{ABSTRACT}

Computational Fluid Dynamics (CFD) technology has been used to assess the exhaust plume pollutant environment of the RD-170 engine hot-firing on the F1 Test Stand at Marshall Space Flight Center. Researchers know that rocket engine hot-firing has the potential for forming thermal nitric oxides $\left(\mathrm{NO}_{\mathrm{x}}\right.$ ), as well as producing carbon monoxide $(\mathrm{CO})$ when hydrocarbon fuels are used. Because of the complicated physics involved, however, little attempt has been made to predict the pollutant emissions from ground-based engine testing, except for simplified methods which can grossly underpredict and/or overpredict the pollutant formations in a test environment. The objective of this work, therefore, has been to develop a technology using CFD to describe the underlying pollutant emission physics from ground-based rocket engine testing. This resultant technology is based on a three-dimensional (3D), viscous flow, pressure-based CFD formulation, where wet $\mathrm{CO}$ and thermal NO finite-rate chemistry mechanisms are solved with a Penalty Function method. A nominal hot-firing of a RD-170 engine on the F1 stand has been computed. Pertinent test stand flow physics such as the multiple-nozzle clustered engine plume interaction, air aspiration from base and aspirator, plume mixing with entrained air that resulted in contaminant dilution and afterburning, counter-afterburning due to flame bucket water-quenching, plume impingement on the flame bucket, and restricted multiple-plume expansion and turning have been captured. The predicted total emission rates compared reasonably well with those of the existing hydrocarbon engine hot-firing test data. 


\section{INTRODUCTION}

Russian-built kerosene fueled engines such as RD-170 or its likeness have been identified as potential candidates to fly the Single-Stage-to-Orbit Rockets. The potential of forming thermal nitric oxides $\left(\mathrm{NO}_{\mathrm{x}}\right)$ and of producing carbon monoxide $(\mathrm{CO})$ has been a concern for ground-based engine testing using hydrocarbon fuels. The release of these criteria pollutants into the atmosphere not only contributes to acid rain and ozone depletion $\left(\mathrm{NO}_{\mathrm{x}}\right)$, but also poses as a potential threat $(\mathrm{CO})$ to living organisms. It is therefore important to predict accurately those criteria pollutant emissions from engine testing for the environmental impact assessment. Several simplified analyses have been used in the past for first principle estimates. For example, thermochemical analysis using chemical equilibrium computer (CEC) $\operatorname{code}^{1}$ can provide CO concentration at nozzle exit plane. However, it over-predicts $\mathrm{CO}$ concentration due to the omission of its subsequent after-burning with air. In addition, it can not predict NO formation unless gross assumption on the amount of air mixing can be made; A perfectly-stirred reactor analysis has been reported to treat the plume-air mixing ${ }^{2}$. Albeit simple, the condition of perfect mixing between the plume and entrained air is not justified. Besides, there is an inherent difficulty in estimating the residence time; Other methods such as steady two-dimensioal analysis of a free exhaust plume can be performed, However, the physics depicted is far from that occurring on a test stand and the evolution of the plume is a transient procéss.

The rapid gains made in CFD and computer technologies have made possible the development of a computational methodology that can describe the pollutant emission physics from ground-based rocket engine testing: 3D air entrainment, 3D multiple-nozzle plume interaction and mixing with air, finite-rate afterburning reaction, plume impingement with flame bucket and plume quenching through deluge water, and 3D restricted multiple plume expansion. In this study, a pressure-based CFD method heavily benchmarked for nozzle, plume, and combustion driven flows was used for this development. The hot-firing of a RD-170 engine on the F1 Stand was simulated. For the purpose of this study, an 11-species, 18-reaction finite-rate chemistry set described the after-burning. A nominal hot-firing with water-quenching (homogeneous two-phase formulation) was computed, along with two cases including the frozen chemistry and finite-rate chemistry (both without water-quenching) for comparison. The emission rates of the pollutants and the exhaust plume properties were computed and the effects of afterburning and water-quenching on the pollutant formation were compared. This resultant technology has potential applications in actual rocket launches and in the development of airbreathing engines.

GOVERNING EQUATIONS 
The present flow solver, Finite Difference Navier-Stokes (FDNS) code ${ }^{3,4,5}$ is used to provide multi-component, steady-state and unsteady viscous flowfield solutions by solving the Reynolds-averaged transport equations such as mass conservation equation, Navier-Stokes equations, energy equation and other scalar transport equations. The general form of these conservation equations can be written as:

$$
\frac{\partial \rho q}{\partial t}+\frac{\partial}{\partial x_{j}}\left\{\rho\left(u-u_{g}\right)_{j} q-\mu_{e} \frac{\partial q}{\partial x_{j}}\right\}=S_{q}
$$

where $\rho$ and $q=\left(1, u, v, w, h, k, \varepsilon\right.$ and $\left.\alpha_{j}\right)$ stand for the fluid density and the flow primitive variables for the continuity, momentum, energy, turbulence model and species mass-fraction equations, respectively. $u_{g}$ stands for the grid moving speed. $\mu_{\mathrm{e}}=\left(\mu_{1}+\mu_{\mathrm{t}}\right) / \sigma$ represents the effective viscosity which is a sum of the laminar viscosity and the turbulence eddy viscosity divided by a turbulence modelling constant ${ }^{5}, \sigma$. The source terms $S_{q}$, for the governing equations in $3 D$ space $x_{i}$ can be written in fully conservative form as:

$$
S_{q}=\left\{\begin{array}{l}
0 \\
-\frac{\partial P}{\partial x_{i}}+\frac{\partial}{\partial x_{j}}\left(\mu_{e} \frac{\partial u_{j}}{\partial x_{i}}\right)-\frac{2}{3} \frac{\partial}{\partial x_{i}}\left(\mu_{e} \frac{\partial u_{j}}{\partial x_{j}}\right) \\
\frac{D P}{D t}+\Phi+Q_{t} \\
\rho(G-\varepsilon) \\
\rho \frac{\varepsilon}{k}\left[\left(C_{1}+C_{3} \frac{G}{\varepsilon}\right) G-C_{2} \varepsilon\right] \\
\omega_{i}, i=1, \ldots . . n
\end{array}\right\}
$$

where $\Phi, Q_{1}$ and $\omega_{i}$ stand for the energy dissipation function, heat source and species source terms, respectively. G stands for the turbulence kinetic energy production rate which is written as:

$$
G=\frac{\mu_{i}}{\rho}\left\{\frac{1}{2}\left(\frac{\partial u_{j}}{\partial x_{i}}+\frac{\partial u_{i}}{\partial x_{j}}\right)^{2}-\frac{2}{3}\left(\frac{\partial u_{k}}{\partial x_{k}}\right)^{2}\right\}
$$

The turbulence modeling constants $C_{1}, C_{2}$ and $C_{3}$ are given as $1.15,1.92$ and 0.25 respectively in the extended $k-\varepsilon$ turbulence model ${ }^{6}$. The extended $k-\varepsilon$ model is superior than the standard $k-\varepsilon$ model $^{7}$ in that a second time scale of the production range of turbulence kinetic energy spectrum is added to the dissipation rate equation. This extra time scale enables the energy transfer mechanism of the turbulence model to respond to the mean strain more effectively. This extended 
k- $\varepsilon$ turbulence model was rigorously benchmarked with fully developed turbulent channel and pipe flows, turbulent free-shear flows, flat plate turbulent boundary layer flow, turbulent flow over a backward-facing step, a confined turbulent swirling flow, and dump combustor flows. The compressibility effect on the turbulence is taken into account by using the method of Mach number correction ${ }^{8,9}$.

\section{SOLUTION ALGORITHM}

To solve the system of nonlinear partial differential equations, it uses finite-difference approximations to establish a system of linearized algebraic equations on non-staggered grid mesh systems. A pressure-based predictor plus multi-corrector time-marching scheme is employed so that flow over all-speed range can be analyzed. The time-marching scheme, total variation diminishing variation (TVD) discretization, and penalty function tretament of the reaction source terms are pertient to this work and are depicted in the following.

\section{Time-Marching Scheme}

The time-marching scheme is described below. For convenience, transformed equation (from $\mathrm{x}_{\mathrm{i}}$ to $\xi_{\mathrm{i}}$ system with $\mathrm{J}$ as the Jacobian of coordinate transformation) of Eq. (1) is written as:

$$
\frac{1}{J} \frac{\partial \rho q}{\partial t}=-\frac{\partial F_{i}}{\partial \xi_{i}}+S_{q}=R_{q}
$$

where $F_{i}$ represents convection and diffusion fluxes in i-direction. First, Eq. (4) is discretized in finite difference form,

$$
\frac{1}{J \Delta t}\left\{(\rho q)^{n+1}-(\rho q)^{n}\right\}=\theta R_{q}^{n+1}+(1-\theta) R_{q}^{n}
$$

where superscripts $n$ and $n+1$ represent old and new time levels respectively. $\theta$ is a time marching control parameter and, $\theta=1.0$ and $\theta=0.5$ are for an implicit Euler and a time-centered time marching schemes, respectively. The following linearization is then incorporated.

$$
(\rho q)^{n+1}=(\rho q)^{n}+\rho^{n} \Delta q^{n}
$$




$$
R_{q}^{n+1}=\left(\frac{\partial R q}{\partial q}\right)^{n} \Delta q^{n}+R_{q}^{n}
$$

With the above approximations, the final form of the time-marching scheme can be written as:

$$
\left\{\frac{\rho^{n}}{J \Delta t}-\theta\left(\frac{\partial R_{q}}{\partial q}\right)^{n}\right\} \Delta q^{n}=R_{q}^{n}
$$

The pressure-based multi-corrector solution method is formulated using simplified perturbed momentum and continuity equations ${ }^{3,45}$. The simplified velocity correction equation can be written as:

$$
\frac{\partial \rho U_{i}}{\partial t} \approx-\nabla P^{\prime}
$$

or, in discrete form,

$$
\begin{aligned}
& u_{i}{ }^{\prime} \approx-\beta \frac{\Delta t}{\rho} \nabla P^{\prime} \\
& P^{n+1}=P^{n}+P^{\prime}
\end{aligned}
$$

where $\beta$ represents a pressure relaxation parameter (typical value of 1.0 ). The velocity and density fields in the continuity equation are then perturbed to form a correction equation. Neglecting higher order terms, the continuity equation can be written as,

$$
\frac{\partial \rho^{\prime}}{\partial t}+\nabla\left(U_{i} \rho^{\prime}\right)+\nabla\left(\rho U_{i}^{\prime}\right)=-\left(\frac{\partial \rho}{\partial t}\right)^{n}-\nabla\left(\rho U_{i}\right)^{n}
$$

Substituting Eq. (10) into (11) and letting $\rho^{\prime}=\mathrm{P}^{\prime} / \mathrm{RT}$, the following all-speed pressure correction equation is obtained,

$$
\frac{M w}{R T} \frac{\partial P^{\prime}}{\partial t}+\nabla\left(U_{i} \frac{M w}{R T} P^{\prime}\right)-\nabla\left(\beta \Delta t \nabla P^{\prime}\right)=-\left(\frac{\partial \rho}{\partial t}\right)^{n}-\nabla\left(\rho U_{i}\right)^{n}
$$

To reduce potential oscillations in the pressure field, an upwind TVD adaptive dissipation term based on the density field, which is described in the next section, is added to the right hand side of Eq. (13). Once solution of Eq. (13) is obtained, the velocity and pressure fields are updated using Eqs. (10) and (11). The density field is then updated through the equation of state. The temperature field can also be modified by using a perturbed temperature correction equation. The entire corrector step is repeated 3 or 4 times such that the mass conservation condition is 
enforced before marching to the next time level. For steady-state flow solutions, however, only one corrector step is used for computational efficiency.

\section{Total Variation Diminishing Discretization}

Second-order central differencing schemes are employed to model the diffusion fluxes and the source terms of the governing equations. High-order upwind schemes are used for the nonlinear terms, convection fluxes, to maintain solution accuracy and to enhance numerical stability. A third-order upwind TVD scheme ${ }^{4}$ is employed in the present flow solver. Only the convection terms are modeled using the TVD flux limiters. The convection terms of the goveming equations can be expressed by finite difference approximation as:

$$
\frac{\partial F}{\partial \xi}=f_{i+1 / 2}-f_{i-1 / 2}+h_{i+1 / 2}-h_{i-1 / 2}
$$

where $f$ and $h$ represent first-order fluxes and TVD flux limiters respectively. The TVD flux limiters are functioned as anti-diffusion terms to recover the scheme to high-order accuracy. The first-order fluxes and the TVD flux limiters are given below.

$$
\begin{aligned}
& f_{i+1 / 2}=\max \left\{0,(\rho U)_{i+1 / 2}\right\} \phi_{i}+\max \left\{0,-(\rho U)_{i+1 / 2}\right\} \phi_{i+1} \\
& h_{i+1 / 2}=\left\{\begin{array}{l}
\frac{1}{4}|\rho U|_{i+1 / 2}\left\{d \phi_{i+1 / 2}^{+}+d \phi_{i-1 / 2}^{-}+\alpha\left(d \phi_{i+1 / 2}^{+}-d \phi_{i-1 / 2}^{-}\right)\right\}, U>0 \\
\frac{1}{4}|\rho U|_{i+1 / 2}\left\{d \phi_{i+1 / 2}^{-}+d \phi_{i+3 / 2}^{+}+\alpha\left(d \phi_{i+1 / 2}^{-}-d \phi_{i+3 / 2}^{+}\right)\right\}, U<0
\end{array}\right.
\end{aligned}
$$

where the minmod functions in the TVD flux limiters are written as:

$$
d \phi_{i+1 / 2}^{ \pm}=\operatorname{sign}\left(\Delta \phi_{i+1 / 2}\right) \max \left\{0, \min \left[\left|\Delta \phi_{i+1 / 2}\right|, \beta \operatorname{sign}\left(\Delta \phi_{i+1 / 2}\right) \Delta \phi_{i+1 / 2 \mp 1}\right]\right\}
$$

The order of accuracy of this scheme is determined by the parameters $\alpha$ and $\beta$. Only the secondorder and third-order upwind schemes were used in this study. That is,

$$
\begin{aligned}
& \alpha= \begin{cases}-1, & 2 n d-\text { order upwind } \\
+\frac{1}{3}, & 3 r d-\text { order upwind }\end{cases} \\
& \beta=\frac{3-\alpha}{1-\alpha}
\end{aligned}
$$


The compression factor, $\beta$, is used to sharpen the contact discontinuities and slip streams for better wave tracking resolution. Other schemes such as second-order and third-order upwind schemes and a second-order central plus fourth-order dissipation scheme are also available, through input data selection, in the present flow solver. The option using central-difference scheme with artifical dissipation has been heavily benchmarked with practical rocket engine nozzle, plume, and combustion driven flow tests and applications such as the Space Shuttle Main Engine (SSME) performance and nozzle/plume flowfields (compared with JANNAF standard codes and hot-fire test data) ${ }^{5}$, SSME start-up and shut-down transients ${ }^{10}$, transient SSME fuel preburner flow ${ }^{11}$, Ramjet dump combustor flows ${ }^{12}$, integrated combustion chamber (SSME, Space Transportation Main Engine, 40k) flow and heat transfer ${ }^{13}$, and base flow characteristics for a four-engine clustered nozzle configuration ${ }^{14}$.

\section{Penalty Function Treatment of the Reaction Source Terms}

For the gas-phase chemical reaction modeling, a general system of chemical reactions can be written in terms of its stoichiometric coefficients $\left(v_{i j}\right.$ and $\left.v_{i j}{ }^{\prime}\right)$ and the $i-t h$ chemical species name $\left(\mathrm{M}_{\mathrm{i}}\right)$ of the $\mathrm{j}$-th reaction as

$$
\sum_{i} v_{i j} M_{i}=\sum_{i} v_{i j}^{\prime} M_{i}
$$

If we define the Arrhenius reaction rate for forward $\left(R_{f j}\right)$ and backward $\left(R_{b j}\right)$,

$$
\begin{aligned}
& R_{f}=K_{f j} \prod_{k}\left(\frac{\rho \alpha_{k}}{M w_{k}}\right)^{v_{k j}} \\
& R_{b j}=K_{b j} \prod_{k}\left(\frac{\rho \alpha_{k}}{M w_{k}}\right)^{v_{w}}
\end{aligned}
$$

the net rate of change in the molar concentration of species $i$ due to reactions $j, R_{i j}$, can be written as:

$$
R_{i j}=M w_{i}\left(v_{i j}^{\prime}-v_{i j}\right)\left(R_{f}-R_{b j}\right)
$$

and the species production rate $\omega_{\mathrm{i}}$ (in terms of mass fraction), is calculated by summing over all reactions,

$$
\omega_{i}=\sum_{j} R_{i j}
$$


The forward reaction rate for each of the reactions is given by the modified Arrhenius law

$$
K_{f_{j}}=A_{j} T^{B_{j}} \exp \left(-\frac{E_{j}}{R T}\right)
$$

and the corresponding backward reaction rate is obtained using

$$
K b_{j}=\frac{K f_{j}}{K e_{j}}
$$

where $\mathrm{Ke}_{\mathrm{j}}$ is the equilibrium coefficient

$$
K e_{j}=(R T)^{-\sum_{i=1}^{n}\left(v_{i j}^{\prime}-v_{i j}\right)} \exp \left[-\frac{\sum_{i=1}^{n}\left(g_{i}^{\prime} v_{i j}^{\prime}-g_{i} v_{i j}\right)}{R T}\right]
$$

To solve the chemistry system equations numerically, an efficient penalty function method $^{15}$ is employed in the present study. In the penalty function method, the system of species equations are solved by employing a small time step size based on the assigned tolerance $(0.01$ used in this study) for species mass fraction equation, that is

$$
\Delta t_{s}=\min \left[\frac{\rho(\Delta \alpha)_{\text {assigned }}}{\omega_{i}}, i=1, n\right]
$$

To ensure species conservation and element balance conditions, the species solutions are subject to the following constraints:

$$
\sum_{i} \alpha_{i}=1.0
$$

and

$$
0.0 \leq \alpha_{i} \leq 1.0
$$

A penalty function is therefore devised to ensure the above constraints are met after every time marching step. This function is defined as

$$
P F_{i}=\frac{1.0-\alpha_{i}^{k}}{\alpha_{i}^{*}-\alpha_{i}^{k}} \quad \text { for } \quad \alpha_{i}^{*}-\alpha_{i}^{k}>0.0
$$




$$
P F_{i}=\frac{-\alpha_{i}^{k}}{\alpha_{i}^{*}-\alpha_{i}^{k}} \quad \text { for } \quad \alpha_{i}^{*}-\alpha_{i}^{k}<0.0
$$

The allowable changes in species mass fractions, which are the solutions of the species continuity equations, are calculated by the following expression such that the second constraint, Eq. (25), is satisfied,

$$
\alpha_{i}^{k+1}=\alpha_{i}^{k}+\left(\alpha_{i}^{*}-\alpha_{i}^{k}\right) \cdot P F
$$

where $P F=\min \left(P F_{i}\right), i=1,2, \cdot \cdots n$. This procedure is a crucial requirement for the numerical stability and accuracy of a the present model. The resulting limited changes are adjusted so that they are proportional to the species source terms from which the first constraint, Eq. (24), is satisfied. For transient reacting flow calculations, multiple steps of the penalty function procedures are used to reach the flow time step size based on the operator-splitting point implicit approach.

\section{BOUNDARY CONDITIONS}

The present flow solver supports various types of boundary conditions for the inlet, exit, symmetry, wall, cyclic/zonal boundaries and singularity lines, etc. For subsonic inlets, fixed total pressure or fixed mass conditions can be specified. For supersonic inlets, all flow variables are fixed unless transient inlet boundary conditions are required. In case of incompressible flow applications, only pressure field is extrapolated at the inlet boundaries. In the present application, the free stream boundary around the nozzles is a modified subsonic inlet with fixed total pressure boundary condition to allow air entrainment. This is accomplished by making two assumptions: 1) air entrainment boundaries are sufficiently far from the nozzles such that the flow is isentropic and irrotational; 2) flow is allowed to entering through the air entrainment bounadries only. Based on assumption 1), Bernoulli's equation is used to solve for the total velocity

$$
q=\left[2\left(P_{o}-P_{e}\right) / \rho_{e}\right]^{0.5}
$$

where subscript $\mathrm{e}$ indicating quantities extrapolated form the interior and $P_{0}$ is the ambient stagnation pressure. Obtaining a total extrapolated velocity from the interior $\mathrm{q}_{e}$, we can compute a total velocity at the air entrainemnt boundary as

$$
q^{n+1}=q_{e}+\omega\left(q-q_{e}\right)
$$


where $\omega$ is defined as a relaxation parameter. The flow directions are then extrapolated from the interior. In order not to violate assumption 2), the total velocity is set to zero if the flow directions indicating an outflow condition and the pressure is set to its ambient value.

RD-170 is a regeneratively cooled, four-nozzle clustered engine which burns Kerosene fuel with liquid oxygen and was used to thrust Energia launch vehicles. Thermochemical analysis ${ }^{1}$ was performed for the thrust chamber at a nominal operating condition and the equilibrium products at the nozzle exit were used as the input to the propulsion system. Table 1 shows the computed flow properties at the chamber, throat and nozzle exit. $\mathrm{CH}_{1.9423}{ }^{1}$ was used as the chemical formula for Kerosene fuel.

Table 1. RD-170 thrust chamber equilibrium flow properties

\begin{tabular}{|l|c|c|c|}
\hline & Chamber & Throat & Nozzle Exit \\
\hline $\mathrm{P}$, atm. & 241.96 & 139.45 & 0.6337 \\
\hline T, deg. K & 3877 & 3667 & 1818 \\
\hline Mach Number & 0.000 & 1.000 & 3.972 \\
\hline Species Mole Fractions & & & \\
$\mathrm{CO}$ & 0.30671 & 0.30035 & 0.24569 \\
$\mathrm{CO}$ & 0.16619 & 0.17879 & 0.26158 \\
$\mathrm{H}$ & 0.02245 & 0.01936 & 0.00016 \\
$\mathrm{HCO}$ & 0.00006 & 0.00004 & 0.00000 \\
$\mathrm{HO}_{2}$ & 0.00010 & 0.00006 & 0.00000 \\
$\mathrm{H}_{2}$ & 0.07551 & 0.07349 & 0.09662 \\
$\mathrm{H}_{2} \mathrm{O}$ & 0.34357 & 0.35801 & 0.39591 \\
$\mathrm{H}_{2} \mathrm{O}_{2}$ & 0.00004 & 0.00002 & 0.00000 \\
$\mathrm{O}$ & 0.00988 & 0.00741 & 0.00000 \\
$\mathrm{OH}$ & 0.05779 & 0.04820 & 0.00004 \\
$\mathrm{O}_{2}$ & 0.01768 & 0.01427 & 0.00000 \\
\hline
\end{tabular}

It can be seen that a significant amount of $\mathrm{CO}(24.569 \%)$ existed at the nozzle exit. This is the amount that could be dumped into the environemnt and can only be chemically reduced through afterburning. It can also be seen that there is no soot nor polycyclic aromatic hydrocarbon fragments produced throughout the thrust chamber, although graphite carbon and polycyclic aromatics were considered. This is to be expected under the nominal RD-170 operating condition at a near stoichiometric equivalence of 1.2939. Regenerative cooling is another factor since there is no need for turbine exhaust dump inside the thrust chamber.

The inlet condition to the flame trench is supersonic and fixed water mass flow rates are specified along the deflector wall and other wall boundaries in the flame trench. The free stream 
around the plume downstream of the trench outlet is frozen at see-level condition with a wind speed of $10 \mathrm{ft} / \mathrm{sec}$. At exit boundaries, direct extrapolation (for supersonic outlet only), fixed mass or fixed pressure at a point boundary conditions can be specified. The fixed pressure boundary condition was used in this study for the downstream plume outlet boundary. For symmetry planes, which are the center planes of the computational domain, zero gradient boundary conditions are applied for all scalars and tangency conditions are imposed for the velocity vectors. Non-slip boundary conditions are employed for the momentum equations at solid wall boundaries. Wall-normal zero gradient pressure boundary conditions are used in the code. Isothermal or adiabatic wall boundary conditions can be specified separately for each wall segment. In the case of turbulent flow computations using high-Reynolds number turbulence models, wall function approaches ${ }^{7,8}$ are employed, which is the case in the present study.

\section{FINITE-RATE AFTERBURNING KINETICS}

To accurately predict the contaminant concentrations of the exhaust plume, finite-rate chemical kinetics are included in the numerical modeling. The plume chemistry occurring in the flame-bucket/Test-stand flow physics includes the afterburning of $\mathrm{CO}$ to $\mathrm{CO}_{2}$, thermal $\mathrm{NO}_{x}$ formation and decomposition, counter-afterburning effect on $\mathrm{CO}$ conversion due to water quenching and its reduction effect on $\mathrm{NO}_{\mathrm{x}}$ formation. These are described with a wet $\mathrm{CO}$ (12 reactions) and a thermal NO (6 reactions) finite-rate mechanisms, as shown in Table 2 . The wellknown Zeldovich mehcanism is included in the thermal NO chemistry. For computational efficiency, only $\mathrm{NO}$ is considered in this work since other species of the $\mathrm{No}_{\mathbf{x}}$ family such as $\mathrm{NO}_{2}$ is converted from NO and usually exists in trace amount. Their existence is hence included in the $\mathrm{NO}$ as "equivalent NO". The wet $\mathrm{CO}$ and thermal NO mechanisms are sub-sets of a combustion kinetics model for complex hydrocarbon (coal derived) fuels developed for Department of Energy ${ }^{16,17,18}$. Their reaction rates, in Arrhenius law form, have been validated with Jet-stirred combustor data, including blow-out limits, shock-tube measurements of ignition delay times ${ }^{17.18}$, and turbulent diffusion flames and flat flames data ${ }^{19}$. In addition, the thermal $\mathrm{NO}_{\mathbf{x}}$ reactions have also been benchmarked with an industrial burner data ${ }^{20}$.

The formation of thermal NO is significantly influenced by flame temperature than other types of NO, e.g., the fuel NO resulting from nitrogen compounds contained in the fuel. Its strong dependence on temperature results from both the temperature dependence of the forward rate constant of reaction $\mathrm{O}+\mathrm{N}_{2}=\mathrm{N}+\mathrm{NO}$ and the sensitivity of $\mathrm{O}$ atom equilibrium concentration to temperature. Production of thermal NO is generally negligible at low temperatures. It is therefore expected that most of the thermal NO will be formed in the flame front, i.e., the plume mixing layer near the exit plane of the nozzles. 
Table 2. Afterburning chemical kinetics

\begin{tabular}{|c|c|c|c|}
\hline Reaction & A & B & E/R \\
\hline & & & \\
Wet COMechanism & & & \\
$\mathrm{H}_{2}+\mathrm{O}_{2}=\mathrm{OH}+\mathrm{OH}$ & $1.7000 \mathrm{E} 13$ & 0 & $2.4070 \mathrm{E} 4$ \\
$\mathrm{OH}+\mathrm{H}_{2}=\mathrm{H}_{2} \mathrm{O}+\mathrm{H}$ & $2.1900 \mathrm{E} 13$ & 0 & $2.5900 \mathrm{E} 3$ \\
$\mathrm{OH}+\mathrm{OH}+\mathrm{O}+\mathrm{H}_{2} \mathrm{O}$ & $6.0230 \mathrm{E} 12$ & 0 & $5.5000 \mathrm{E} 2$ \\
$\mathrm{O}+\mathrm{H}_{2}=\mathrm{H}+\mathrm{OH}$ & $1.8000 \mathrm{E} 10$ & 1.0 & $4.4800 \mathrm{E} 3$ \\
$\mathrm{H}+\mathrm{O}_{2}=\mathrm{O}+\mathrm{OH}$ & $1.2200 \mathrm{E} 17$ & -0.91 & $8.3690 \mathrm{E} 3$ \\
$\mathrm{M}+\mathrm{O}+\mathrm{H}=\mathrm{OH}+\mathrm{M}$ & $1.0000 \mathrm{E} 16$ & 0 & 0 \\
$\mathrm{M}+\mathrm{O}+\mathrm{O}=\mathrm{O}_{2}+\mathrm{M}$ & $2.5500 \mathrm{E} 18$ & -1.0 & $5.9390 \mathrm{E} 4$ \\
$\mathrm{M}+\mathrm{H}+\mathrm{H}=\mathrm{H}_{2}+\mathrm{M}$ & $5.0000 \mathrm{E} 15$ & 0 & 0 \\
$\mathrm{M}+\mathrm{H}+\mathrm{OH}=\mathrm{H}_{2} \mathrm{O}+\mathrm{M}$ & $8.4000 \mathrm{E} 21$ & -2.0 & 0 \\
$\mathrm{CO}+\mathrm{OH}=\mathrm{H}+\mathrm{CO}$ & $4.0000 \mathrm{E} 12$ & 0 & $4.0300 \mathrm{E} 3$ \\
$\mathrm{CO}+\mathrm{O}_{2}=\mathrm{CO}+\mathrm{O}$ & $3.0000 \mathrm{E} 12$ & 0 & $2.5000 \mathrm{E} 4$ \\
$\mathrm{CO}+\mathrm{O}+\mathrm{M}=\mathrm{CO}+\mathrm{M}$ & $6.0000 \mathrm{E} 13$ & 0 & 0 \\
& & & \\
Thermal NOMechanism & & & \\
$\mathrm{O}+\mathrm{N}_{2}=\mathrm{N}+\mathrm{NO}$ & $1.3600 \mathrm{E} 14$ & 0 & $3.7750 \mathrm{E} 4$ \\
$\mathrm{~N}_{2}+\mathrm{O}_{2}+\mathrm{NO}+\mathrm{NO}$ & $9.1000 \mathrm{E} 24$ & -2.5 & $6.4600 \mathrm{E} 4$ \\
$\mathrm{NO}+\mathrm{O}=\mathrm{O}_{2}+\mathrm{N}$ & $1.5500 \mathrm{E} 9$ & 1.0 & $1.9450 \mathrm{E} 4$ \\
$\mathrm{M}+\mathrm{NO}=\mathrm{O}+\mathrm{N}+\mathrm{M}$ & $2.2700 \mathrm{E} 17$ & -0.5 & $7.4900 \mathrm{E} 4$ \\
$\mathrm{~N}+\mathrm{OH}=\mathrm{NO}+\mathrm{H}$ & $4.0000 \mathrm{E} 13$ & 0 & 0 \\
$\mathrm{CO}+\mathrm{N}=\mathrm{CO}+\mathrm{NO}$ & $2.0000 \mathrm{E} 11$ & -0.5 & $4.0000 \mathrm{E} 3$ \\
& & \\
\hline
\end{tabular}

* M stands for third-body collision partner

\section{COMPUTATIONAL GRID GENERATION}

The grid generation for the nozzles and test stand was performed using an EZSURF code $^{21}$. It was used to interactively create the edge curves of the nozzle exits, aspirator, flame deflector and multi-zone block edges. The initial surfaces were then generated using transfinite interpolation in EZSURF. The flame deflector and nozzle exit surfaces were then elliptically smoothed. Further work was done on the nozzle exit surfaces using Bezier curve and local redistribution in EZSURF. The volume grid for the first block (Zone 1) was created using two linear stackings; one from the top of the block to the nozzle exit plane and then another form the 
nozzle exit plane to the bottom of the aspirator. The flame deflector block (Zone 2) and subsequent external ambience (Zone 3) volume grids were created using transfinite interpolation.

The F1 Test Stand, standing 230 feet tall with a flame bucket (deflector) attached to the aspirator, was used to test F1 engines with which Saturn launch vehicles were propelled. Not only does the flame bucket quenches the rocket exhaust plume with deluge water, but also turns the vertical flowing exhaust plume to that of a horizontal direction, after which the plume expands and dissipates into the atmosphere. Fig. 1 shows the computational domian for the F-1 Stand. The RD-170 engine is mounted vertically, firing down into the flame bucket. Due to symmetry, only half of the domain was actually computed. The four RD-170 nozzles (mounted beneath the platform that is not modeled) and the aspirator are described by Zone 1 which contains 63,360 grid points $(72 \times 40 \times 22)$. The aspirator itself is mounted on top of the flame bucket such that the air entrainment can be promoted and the plumes are centered while impinging at a predetermined area in the flame bucket (approximately 45-degree elbow at the bottom). Ambient air is allowed to be entrained through the top and four side boundaries of Zone 1. The flame bucket is modeled by Zone 2 which composes of 72,000 grid points $(72 \times 40 \times 25)$. The plumes are then quenched through water deluge injecting from all four walls inside the bucket. The water injection pattern is designed as such that most of the water injects at the plume impingement area.

After passing through the flame bucket (Zone 2), the quenched plumes expand into the vast surrounding atmosphere (Zone 3 ) which is described by 156,975 grid points $(91 \times 69 \times 25)$. The relative sizes and loactions of all three zone are shown in Fig. 2. Total number of grid points used in this study was 292,335 .

\section{RESULTS AND DISCUSSION}

A frozen chemistry analysis was performed at first for a small period of elapsed time in order to establish an initial plume in the system. This not only prepared for the initial flowfields for the computation of subsequent parallel finite-rate chemistry and finite-rate chemistry with water-quenching cases, but also served as an excellent check of mass conservation using carbon balance. This procedure is allowed since the total pollutant emission rates during a nominal steady RD-170 hot-firing are desired and not those of an actual start-up sequence. The goals are therefore to compute the growth rate of $\mathrm{NO}$ and the disappearance rate of $\mathrm{CO}$ until they achieve asymptotic states.

Fig. 3 shows the computed velocity vectors colored by Mach number contours to represent the entrained air surrounding the bulk rocket plumes. Entrained from surroundings close to the open platform, the air accelerated and mixed with the plume bounadry layer and 
entered the opening of the aspirator, where it continuously mixed with the advancing plume bounadry layer. In addition to cooling and dilution of the contaminant, the entrained air also provides the source of reactants for afterburning and thermal NO formation. Due to a backwardfacing step geometry between the aspirator and the flame bucket, flow recirculation patterns formed underneath the aspirator.

Fig. 4 shows the computed temperature contours for the water-quenching case. Water jet vectors are shown for the top and bottom walls. The water jets at the back wall are mostly blocked out by the center temperature contours, whereas the water jets from the front wall are not shown for clarity. Most of the thermal NO is formed near the aspirator level where it has the most mixing and the hottest temperature. This is in agreement with the characteristics of the Zeldovich mechanism. It can also be seen that the plumes impinge on the 45-degree bend section of the flame bucket where it encounters the most water-quenching, that agrees with the original design. The quenched plumes then turn and partially hit the outer wall, where it moves horizontaly out, following the direction of the flame bucket.

Fig. 5 shows the comparisons of averaged mass fraction in the system for species $\mathrm{CO}$, $\mathrm{CO}$, $\mathrm{NO}$ and $\mathrm{OH}$, with respect to elapsed time. The averaged mass fraction for $\mathrm{CO}$ in the add water-quenching case is more than that of the purely finite-rate chemistry case due to the counter after-burning effect of deluge water, and vice versa for that of $\mathrm{CO} 2$. The higher level of $\mathrm{OH}$ in the finite-rate case shows a higher degree of after-burning reaction, due to higher overall plume temperature without water-quenching. Total NO production drops significantly in the add waterquenching case. The concentraion of NO in the add water-quenching case is almost two orders of magnitude lower than that in the finite-rate chemistry only case. This is not surprising since the extent of thermal NO formation depends heavily on the local temperature. The effect of water deluge on the formation of NO is the reduction in peak temperature caused by the heat capacity of water.

The computed growth of plume volumes is shown in Fig. 6. It can be seen that the growth rates of the plumes have reached their approximate asymptotic states. Obviously, the plume energy of the finite-rate chemistry is higher than that of the add water-quenching case. Correspondingly, the plume volume growth rate of the finite-rate case is larger than that of the add water-quenching case. It is anticipated that the characteristics of computed growth of plume energies would be similar to those of plume volumes. These CFD results ultimately serve as the basis (input) for the subsequent meteorological cloud dispersion calculation, where the plume volume growth rate helps determining the eventual plume size and the plume energy growth rate helps determining the magnitude the plume buoyancy force.

A comparison of the calculated criteria pollutant total emission rates for RD-170 with those measured for other Kerosene-fueled engines ${ }^{22}$ is shown in Table 3. Since thrust levels are quite different, the measured emission rates were extrapolated to a RD-170 level by thrust ratios. Although the operations of the engines and test stands are vastly different, and there is a question on whether the point sampling technique used in the measurement representative of the whole 
plume. The agreement in terms of order-of-magnitude for these engines is reasonable and encouraging. Among RD-170 CFD computations, the emission rate of $\mathrm{CO}$ is maximum and that of NO is zero for the frozen chemistry case, since afterburning reactions are not turned on, whereas the effect of water deluge has reduced the $\mathrm{CO}$ conversion rate from $83 \%$ of the finiterate chemistry case to that of $67 \%$. This is of interest since the effect of water deluge also has reduced the $\mathrm{NO}_{\mathrm{x}}$ production by $95 \%$.

Table 3. Total emission rates

\begin{tabular}{|l|c|c|c|}
\hline Engine & Thrust, lbf & NO $_{\mathbf{x}} \mathrm{lb} / \mathrm{sec}$ & CO, lb/sec \\
\hline MA5B/hot-firing & 370,000 & $5.4 / 25.9^{*}$ & $133 / 641^{\circ}$ \\
\hline MA3S/hot-firing & 165,000 & $2.7 / 29.1^{\circ}$ & $210 / 2,266^{*}$ \\
\hline MA3B/hot-firing & 60,000 & $1.5 / 45.6^{\circ}$ & $138 / 4,111^{*}$ \\
\hline RS27/hot-firing & 205,000 & $1.2 / 10.6^{\circ}$ & $94 / 820^{\circ}$ \\
\hline RD-170/CFD & & & 1,382 \\
\hline Frozen & $1,777,000$ & - & 232 \\
\hline Finite-Rate & $1,777,000$ & 8.0 & 463 \\
\hline Add Water & $1,777,000$ & 0.4 & \\
\hline
\end{tabular}

based on extrapolation of measured emission rate to a $\mathrm{RD}-170$ by thrust ratio

\section{CONCLUSION}

A 3D viscous flow, pressure based CFD technology has been developed to predict the contaminant emissions from ground-based rocket engine RD-170 propulsion testing. Pertinent test stand flow physics such as the multiple-nozzle clustered engine plume interaction, aspiration from base and aspirator, plume mixing with entrained air that resulted in contaminant dilution and afterburning, counter-afterburning due to flame bucket water-quenching, plume impingement on the flame bucket, and restricted multiple-plume expansion and turning, have been predicted. The predicted criteria pollutant total emission rates agreed reasonably well with those of the existing hydrocarbon engine hot-firing test data. This resultant technology has potential applications in actual rocket launches and in the development of air-breathing engines. 


\section{ACKNOWLEDGEMENT}

The authors thank the support from Robert Schwinghamer of NASA Operational Environment Team. The discussions with Rebecca McCaleb and Clay Horan of Environmental and Engineering Office were also appreciated. We would also like to thank Catherine Dumas of Sverdrup for making the iso-value graphics and flowfield animation.

\section{REFERENCES}

1 Svehla, R.A., and McBride, B.J., "FORTRAN IV Computer Program for Calculation of Thermodynamic and Transport Properties of Complex Chemical Systems," NASA TN D-7056, 1973.

${ }^{2}$ Leone, D.M., and S.R. Turns, "Active Chlorine and Nitric Oxide Formation From Chemical Rocket Plume Afterburning," AIAA Paper 94-0788, January 1994.

${ }^{3}$ Chen, Y.-S., "Compressible and Incompressible Flow Computations with a Pressure Based Method," AIAA Paper 89-0286, January 1989.

${ }^{4}$ Chen, Y.-S., Liaw, P., Shang, H.-M., and Chen, C.-P., "Numerical Analysis of Complex Internal and External Viscous Flows with a Second-Order Pressure-Based Method," AIAA Paper 932966, July 1993.

${ }^{5}$ Wang, T.-S. and Chen Y.-S., "Unified Navier-Stokes Flowfield and Performance Analysis of Liquid Rocket Engines," Journal of Propulsion and Power, Vol. 9, No. 5, 1993, pp.678-685.

${ }^{6}$ Chen, Y.-S., and Kim, S.W., "Computation of Turbulent Flows Using an Extended k- $\varepsilon$ Turbulence Closure Model," NASA CR-179204, Oct. 1987.

7 Launder, B.E., and D.B. Spalding, "The Numerical Computation of Turbulent Flows," Computer Methods in Applied Mechanics and Engineering, Vol. 3, No. 2, 1974, pp.269-289.

${ }^{8}$ Chen, Y.-S., Cheng, G.-C., and Farmer, R.C., "Reacting and Non-Reacting Flow Simulation for Film Cooling in 2-D Supersonic Flows," AIAA Paper 93-3602, July 1992.

9 Cheng, G.-C., Farmer, R.C., and Chen, Y.-S., "Numerical Study of Turbulent Flows with Compressibility Effects and Chemical Reactions," AIAA Paper 94-2026, June 1994. 
${ }^{10}$ Wang, T.-S., "Numerical Study of the Transient Nozzle Flow Separation of Liquid Rocket Engines," Computational Fluid Dynamics Journal, Vol.1, No.3, Oct. 1992, pp. 319-328.

${ }^{11}$ Wang, T.-S., Chen, Y.-S., Farmer, R. C., and Tucker, P. K., "Numerical Investigation of the Transient SSME Fuel Preburner Combustor Flowfield," AIAA Paper 90-0646, January 1990.

${ }^{12}$ Wang, T.-S., Chen, Y.-S., and Farmer, R. C., "Numerical Study of Reactive Ramjet Dump Combustor Flowfield with a Pressure Based CFD Method", AIAA Paper 89-2798, July 1989.

${ }^{13}$ Wang, T.-S., and Luong, V., "Hot-Gas-Side and Coolant-Side Heat Transfer in Liquid Rocket Engine Combustors," Journal of Thermophysics and Heat Transfer, Vol. 8, No. 3, 1994, pp. 524530 .

${ }^{14}$ Wang, T.-S., "Numerical Analysis of Base Flowfield at High Altitude for a Four-Engine Clustered Nozzle Configuration," AIAA Paper 93-1923, June 1993.

${ }^{15}$ Chen, Y.-S., and Farmer, R.C., "Computations of Premixed and Diffusion Flames with a Fast Chemistry Integration Scheme," 4th International Symposium on CFD, U.C. Davis, 1991, pp.172177.

${ }^{16}$ Edelman, R.B., R.C. Farmer, and T.-S. Wang, "Combustion and Emissions of Synthetic Fuel Components - Analysis and Modeling," Combustion of Synthetic Fuels, American Chemical Society Symposium Series 217, 1983, pp. 29-48.

${ }^{17}$ Wang, T.-S., Farmer, R. C., and Tucker, P. K., "Turbulent Hydrocarbon Combustion Kinetics Stochastic Modeling and Verification," AIAA Paper 89-0486, January 1989.

${ }^{18}$ Wang, T.-S., Farmer, R. C., and Edelman, R. B., "Turbulent Combustion Kinetics for Complex Hydrocarbon Fuels," AIAA Paper 88-0733, January 1988.

${ }^{19}$ Edelman, R.B., and P.T. Harsha, "Some Observations on Turbulent Mixing with Chemical Reactions," Turbulent Combustion, Progress in Astronautics and Aeronautics, Vol. 58, pp.55$101,1978$.

${ }^{20}$ Harsha, P. T., Edelman, R. B., Wang, T.-S., and Farmer, R. C., "Performance Modeling of Advanced Gas Burner Systems," GRI-82/0016, SAI 82-041-CHA, June 1982.

${ }^{21}$ Warsi, S., "Algebraic Surface Grid Generation in Three-Dimensional Space," NASA CP-3143, April 1992.

${ }^{22}$ Anon, "Estimation of Pollutants in Rocket Exhuast," Final Report, Rockwell International, May 1984. 


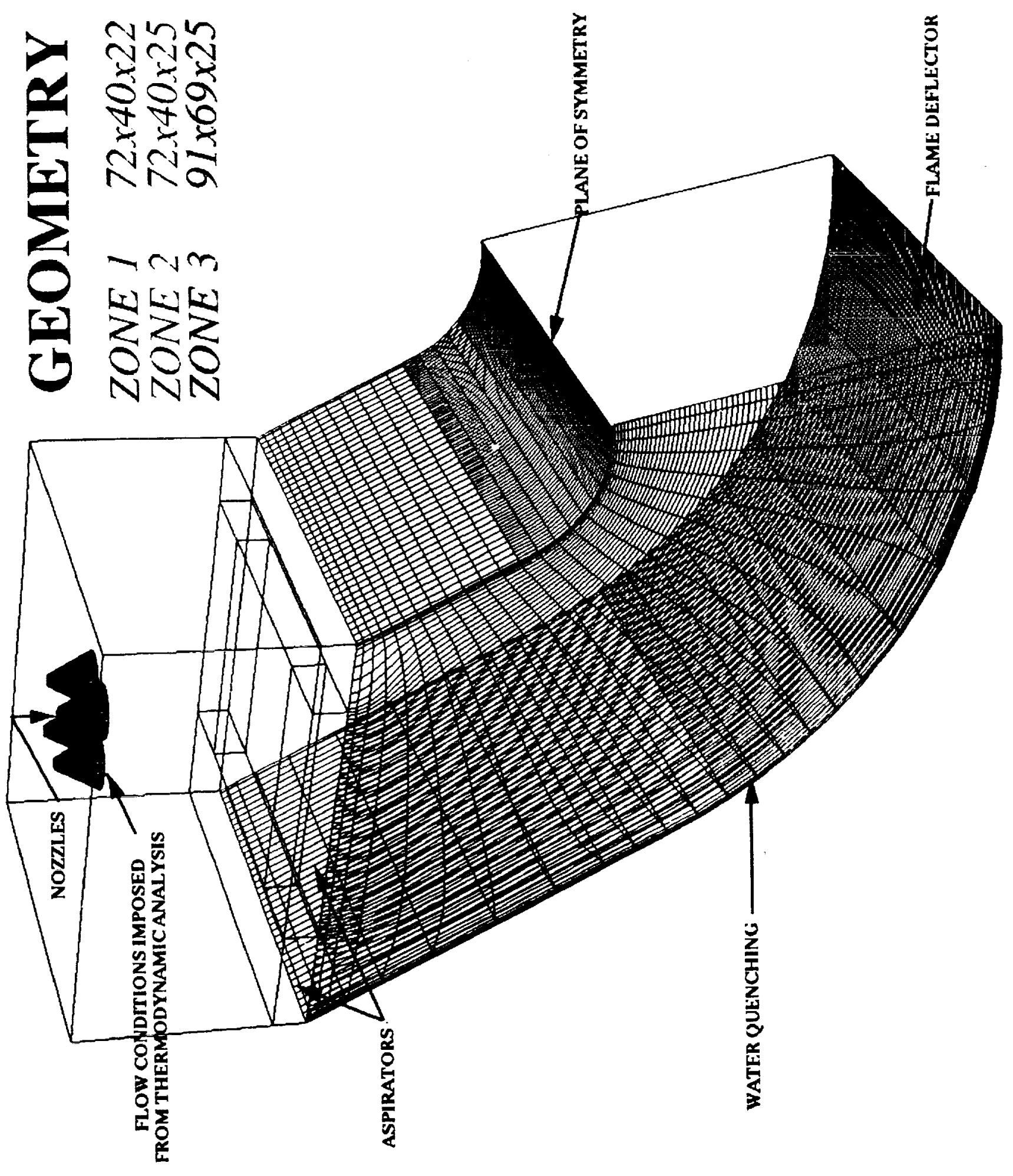

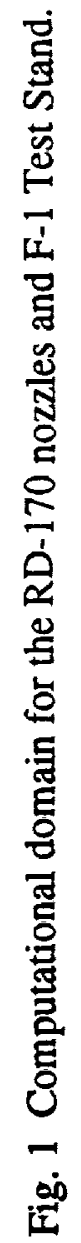




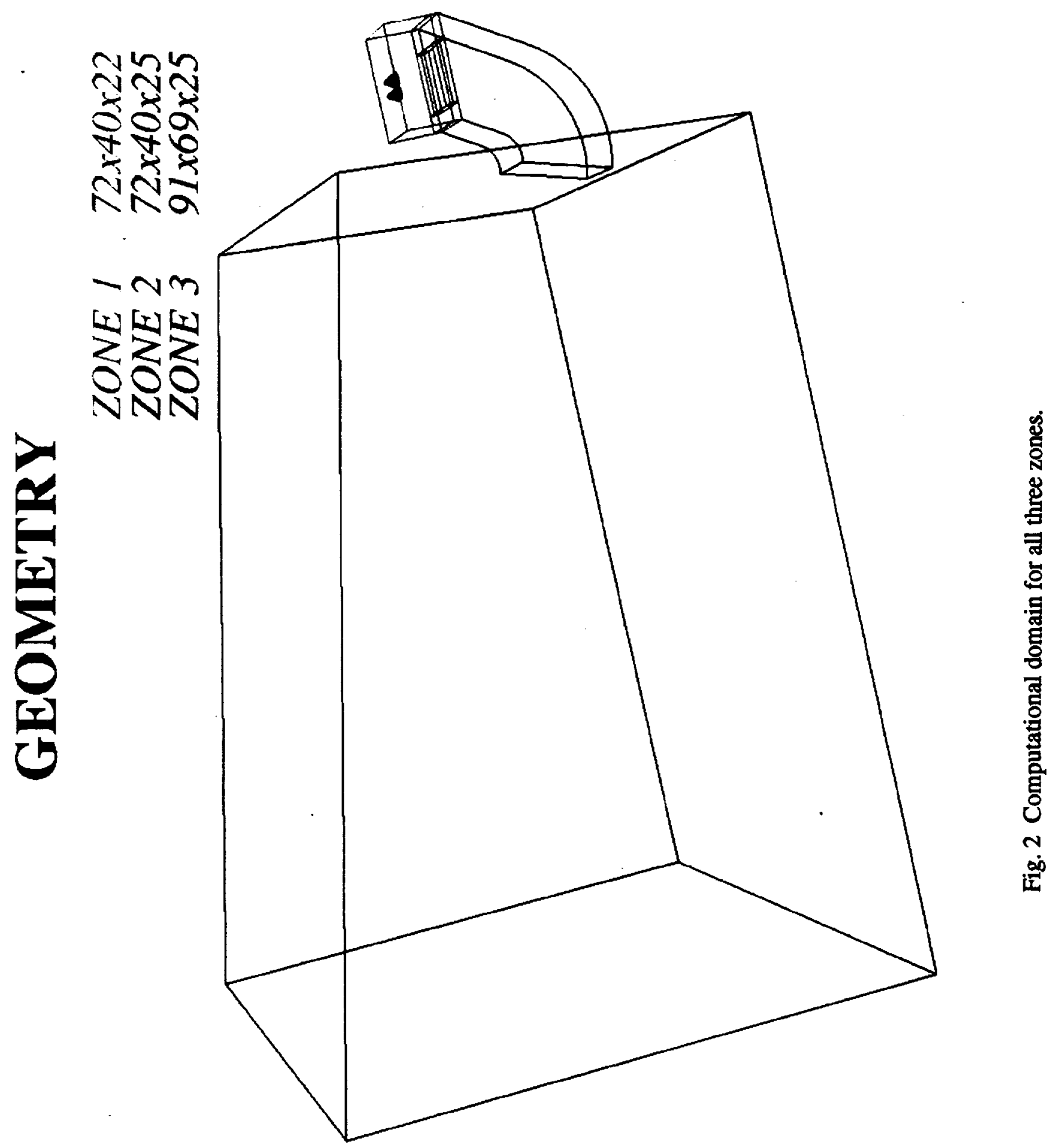




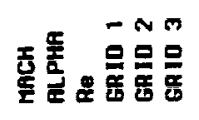

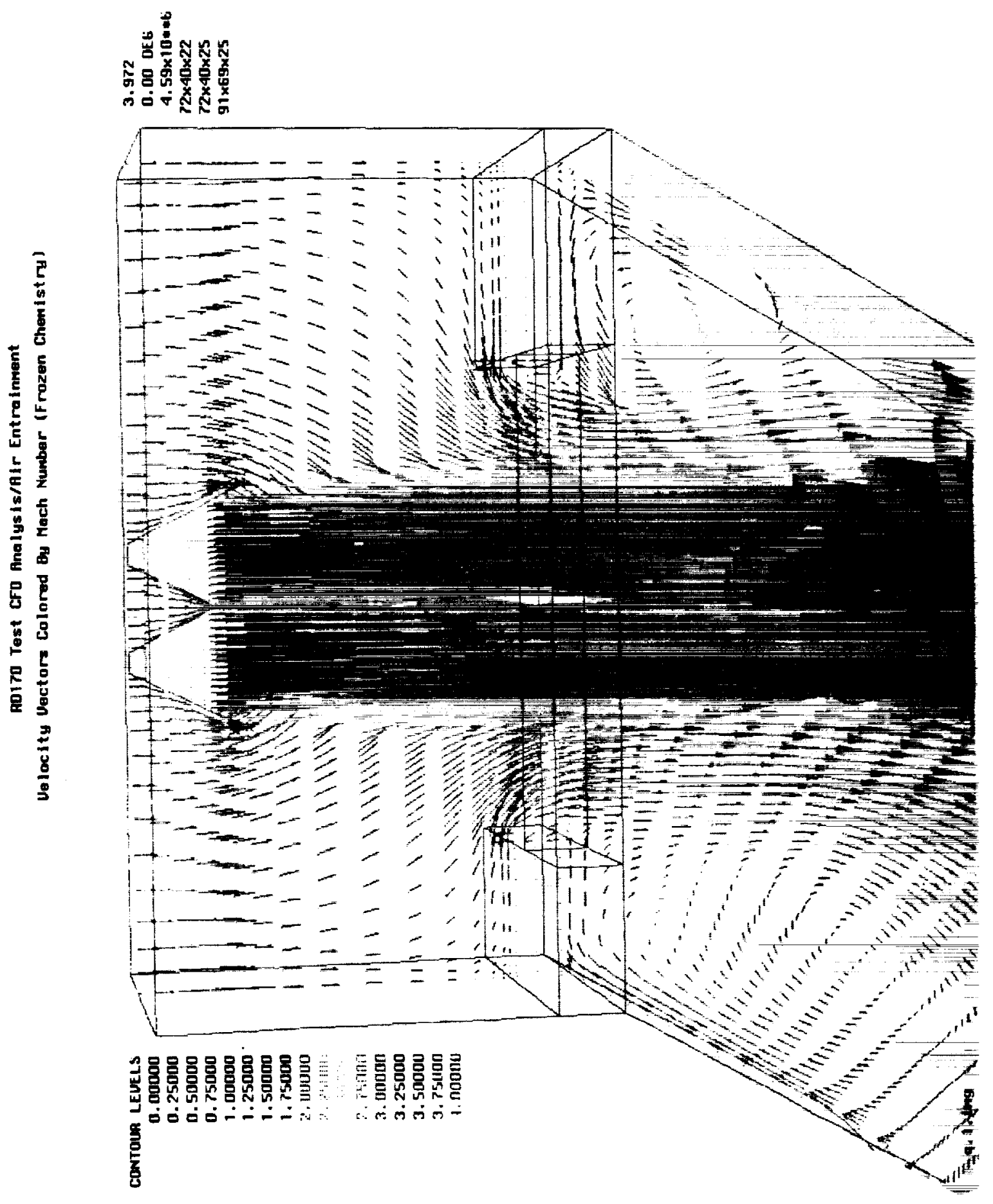

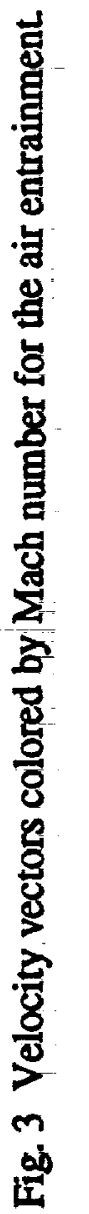



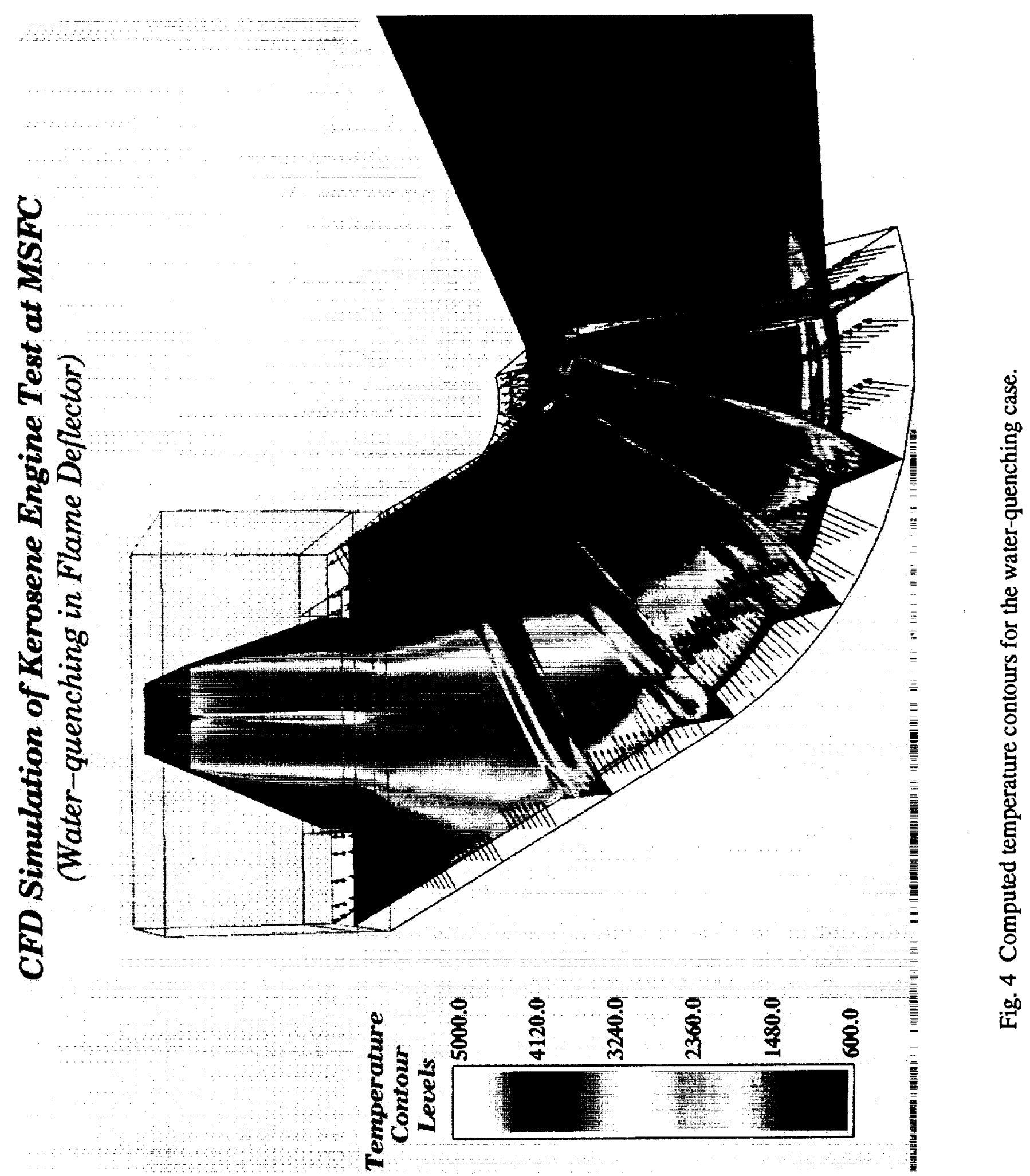


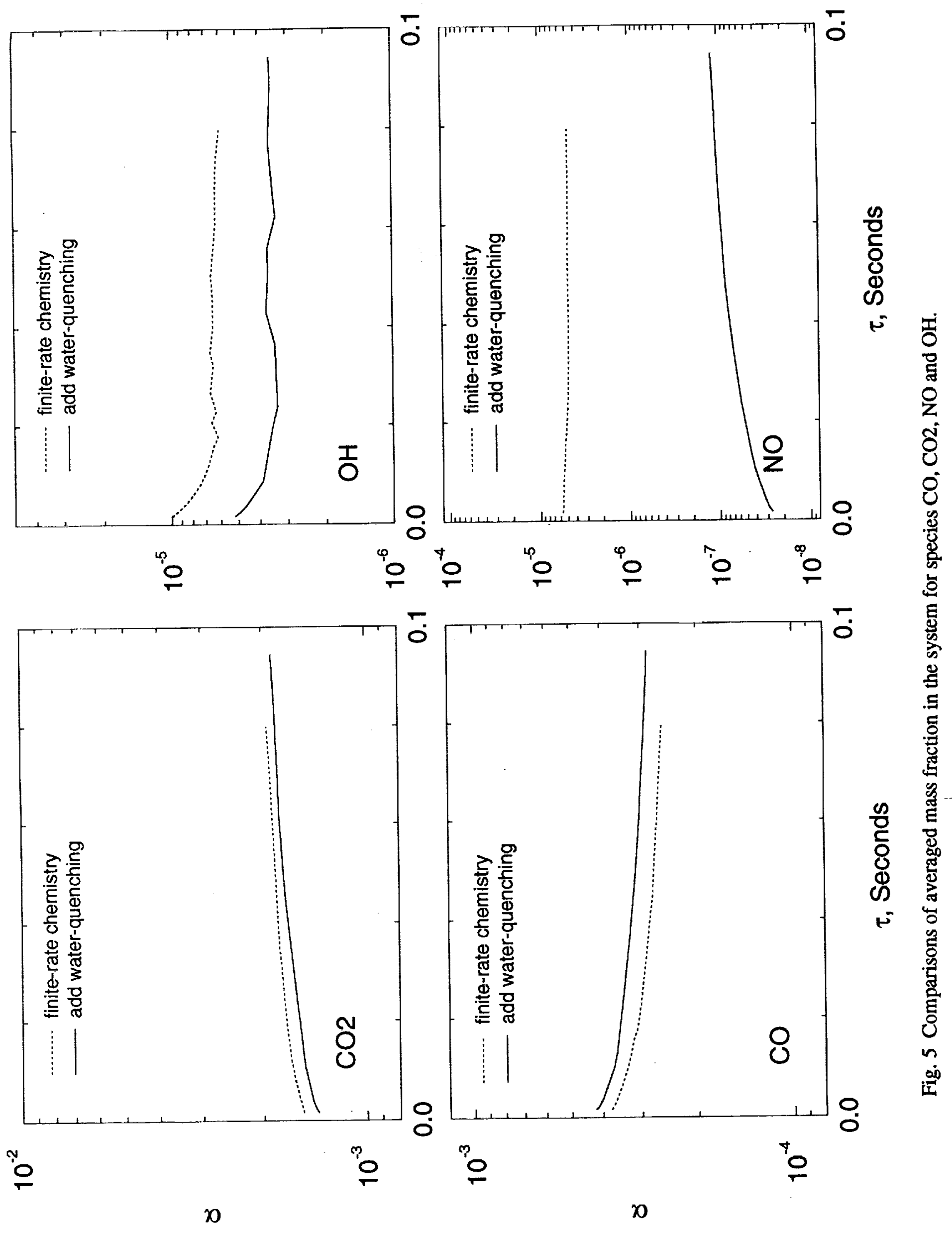




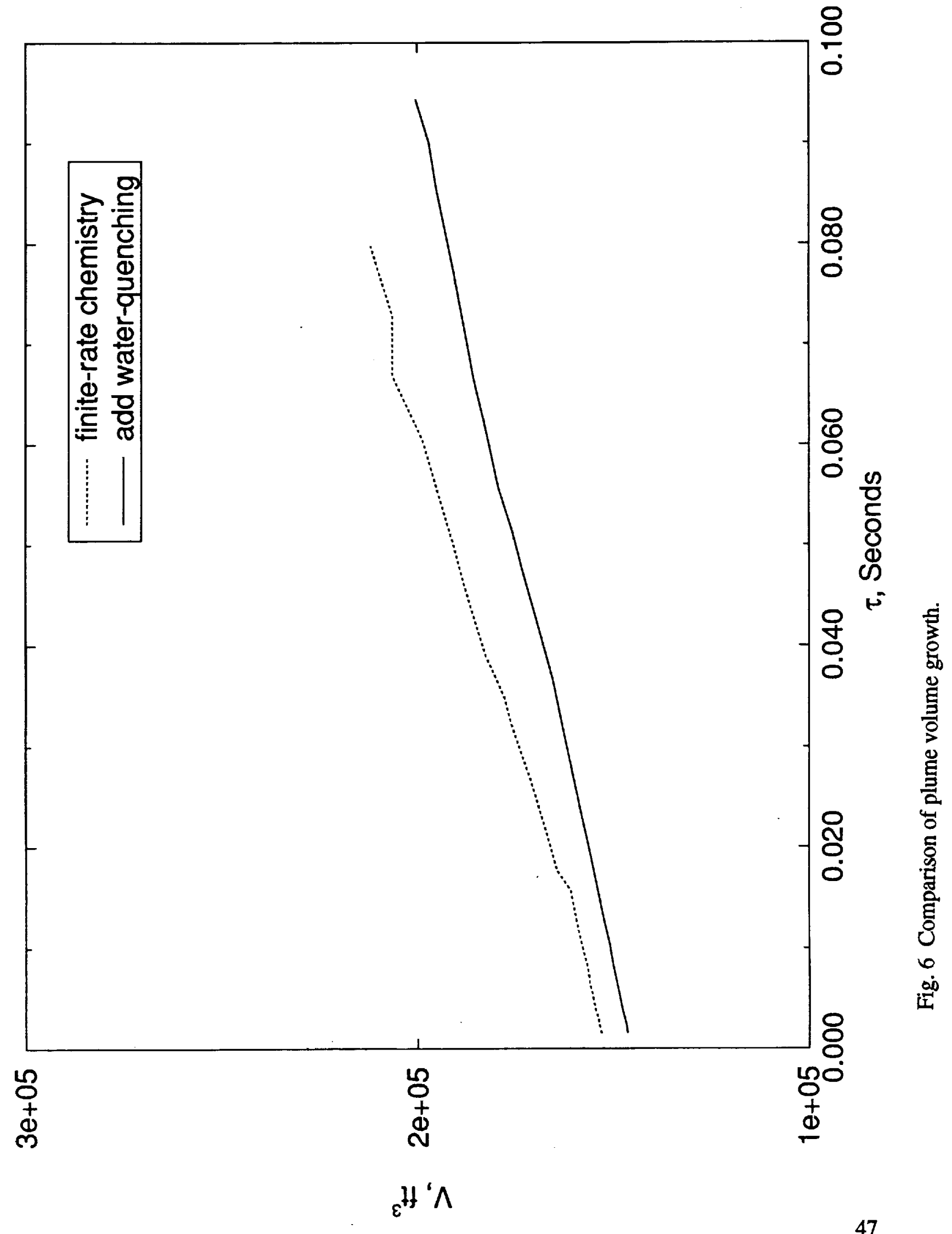


